\title{
Exploração de fosfato na Bodoquena-MS - Um estudo aplicado utilizando o método da eletrorresistividade
}

Marieli Machado Zago로 Maximilian Fries ${ }^{1}$, Eduardo Antônio Abrahão Filho², Lucas Nery², Letícia Martins²

${ }^{1}$ Laboratório de Geofísica Aplicada - LGA, Universidade Federal do Pampa; ${ }^{2}$ Geólogo(a) EDEM.

Copyright 2018, SBGf - Sociedade Brasileira de Geofísica

Este texto foi preparado para a apresentação no VIII Simpósio Brasileiro de Geofísica, Salinópolis, 18 a 20 de setembro de 2018. Seu conteúdo foi revisado pelo Comitê Técnico do VIII SimBGf, mas não necessariamente representa a opinião da SBGf ou de seus associados. E proibida a reprodução total ou parcial deste material para propósitos comerciais sem prévia autorização da SBGf.

\section{Resumo}

Inserido no contexto geomorfológico do Planalto da Bodoquena, no centro oeste brasileiro, encontra-se zonas fosfáticas com alto potencial exploratório para a fabricação de fosfato natural reativo. O presente estudo utiliza a geofísica no auxílio à identificação dos contrastes de propriedades físicas em subsuperfície no depósito de minério de fosfatos denominado de Ressaca localizado no município de Bonito, Estado do Mato Grosso do Sul. Utilizou-se o método geofísico de eletrorresistividade para delimitar a superfície da camada de minério até o topo do minério primário e identificar possíveis feições cársticas (cavidades). A partir da resistividade elétrica obtida foi possível identificar contrastes entre camadas intemperizadas e rocha sã. Também, comprovou-se a ausência de zonas cársticas no local, hipótese inicialmente proposta.

\section{Introdução e objetivos}

O minério de fosfato é um fertilizante natural para aplicação direta sem acréscimo de beneficiamento químico e tem grande importância na produtividade do setor agrícola. A carência de fertilizantes fosfatados no cultivo de culturas (arroz, soja, milho) causa o retardo do crescimento e fraco desenvolvimento das plantas (Lapido-Loureiro e Nascimento, 2003). No depósito Ressaca encontra-se predominantemente rochas do tipo carbonáticas e pelíticas, que hospedam mineralizações fosfáticas.

Para a exploração do fosfato é preciso realizar intensas pesquisas na área estudada. Dentre os métodos exploratórios utilizados, o uso do método geofísico de eletrorresistividade permite detectar de forma não invasiva e indireta variações laterais e em profundidade da resistividade no subsolo, sendo muito adequado para detectar contatos geológicos verticais ou inclinados, estruturas antrópicas, mineralizações, diques, fraturamentos e/ou falhamentos, determinação de nível freático, caracterização de aquíferos e outros corpos ou estruturas que se apresentem como heterogeneidades laterais destes parâmetros (Telford et. al, 1990; Dentith \& Mudge, 2014).

O objetivo principal deste estudo consiste no uso do método geofísico de eletrorresistividade para a detecção do limite zonas superficiais intemperizadas (saprólito) rocha sã e identificação de cavidades (zonas cársticas). Especificamente os resultados visam auxiliar no detalhamento geológico, otimização na localização de sondagens, análise e caracterização das ocorrências de fosfato em subsuperfície

A área de estudo localiza-se no município de Bonito, Estado do Mato Grosso do Sul, distante cerca de $35 \mathrm{~km}$ do município de Bodoquena no estado do Mato Grosso do Sul. (Figura 1).

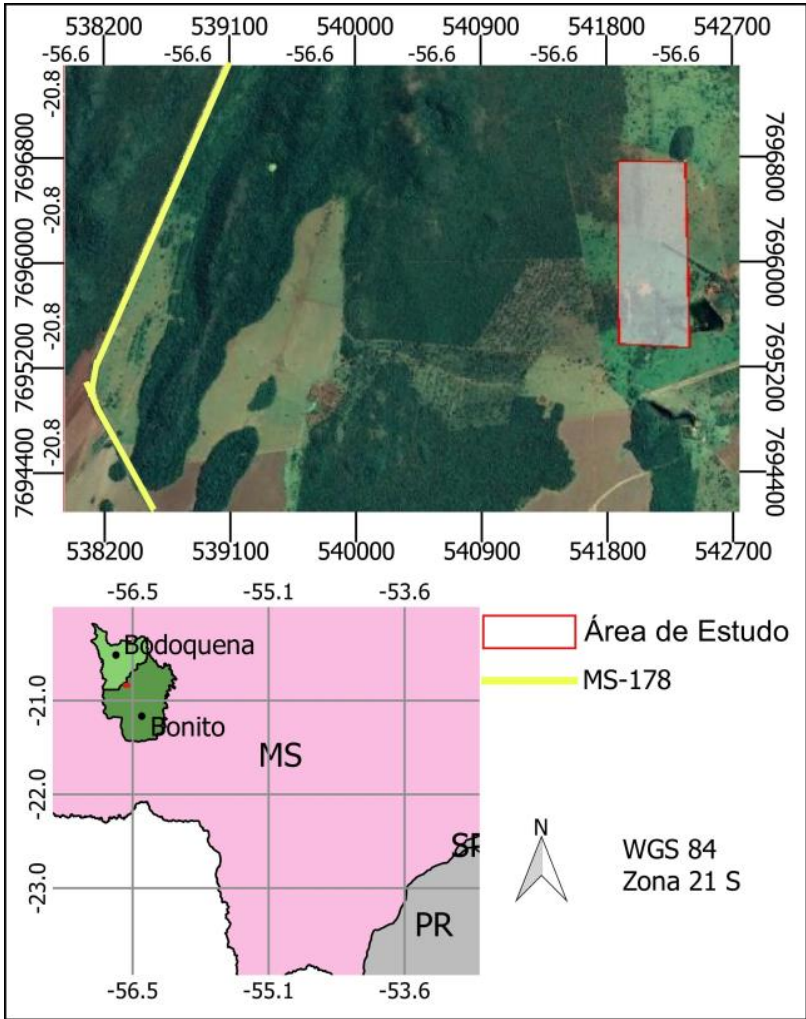

Figura 1 - Localização da área de estudo (adaptado de CPRM 2010).

\section{Contexto geológico e localização dos perfis}

Regionalmente a área de estudo está inserida no contexto geomorfológico da Serra ou Planalto da Bodoquena, posicionada na porção central da Plataforma Sul-Americana, centro oeste brasileiro. O planalto se estende por cerca de $300 \mathrm{~km}$ segundo orientação N-S, com largura em torno de $40 \mathrm{~km}$ e cotas variando de $300 \mathrm{a}$ 650 metros. A região pertence à porção norte da Faixa Paraguai, a qual estabelece contatos colisionais com o Cráton Amazônico a oeste e noroeste. A Faixa encontrase em discordância erosiva com sedimentos paleomesozóicos da Sinéclise do Paraná, sobrepostos por sedimentos cenozoicos da Bacia do Pantanal (CPRM, 1999). 
As principais litologias da área de estudo pertencem ao Grupo Corumbá, estratigraficamente posicionado no topo da Faixa Paraguai no contato entre as Formações Bocaina e Tamengo. Essas unidades são constituídas de sequências plataformais carbonáticas e pelíticas (Boggiani, 1997).

As rochas das Formações Bocaina e Tamengo hospedam mineralizações fosfáticas e são envelopadas e embasadas por calcários dolomíticos, fosforitos, brechas fosfáticas e calcários fosfáticos, controlados por dobras fechadas com vergência para oeste (Boggiani, 1997) (Figura 2). Sobre essas rochas encontram-se porções contínuas de saprólito e solo enriquecidos em fósforo que refletem o minério fosfático secundário.

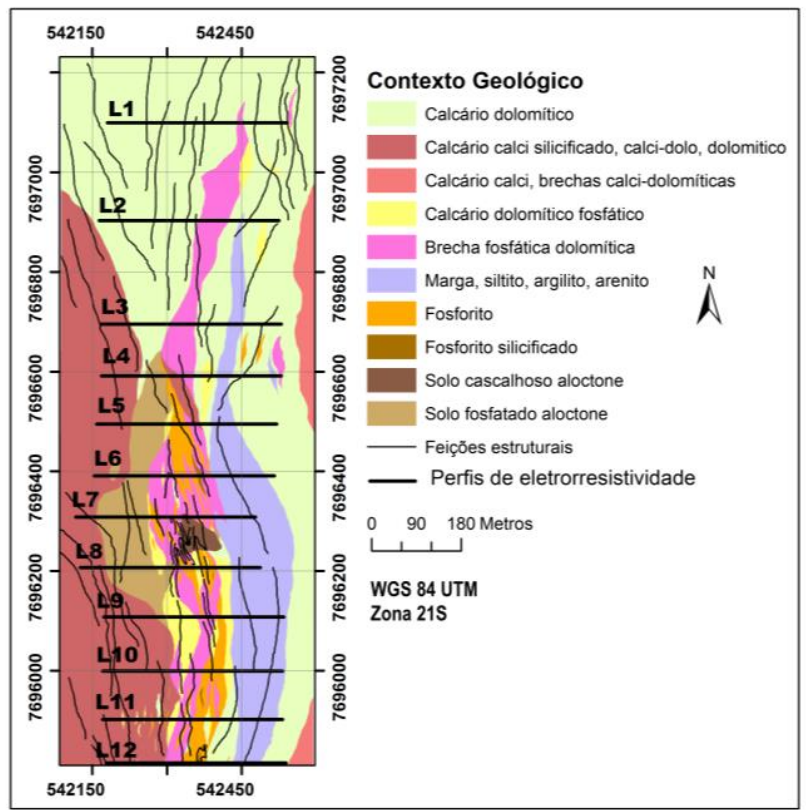

Figura 2 - Contexto geológico da área de estudo e perfis de eletrorresistividade programados. Fonte: Adaptado de EDEM, 2017.

\section{Metodologia/ Problema Investigado}

O planejamento e desenvolvimento da campanha geofísica foi efetuado tendo-se o contexto geológico e estrutural da área. Foram planejados 12 perfis com 360 metros de extensão e direção E-W seccionando as principais litologias e estruturas na área (Figura 2).

Para as medidas de resistividade foi utilizado um resistivímetro modelo Syscal Pro fabricado pela Iris Instruments. Foram empregados 4 multicabos de 90 metros de extensão e 72 eletrodos. O equipamento é de propriedade da Universidade Federal do Pampa Unipampa, Campus Caçapava do Sul.

As geometrias de arranjos de eletrodos utilizados no presente trabalho foram wenner schlumberger e polo dipolo. As sequências de eletrodos foram desenvolvidas com o auxílio do software Electre II (Fabricado pela Iris Instruments):

- Arranjo Wenner Schulumberger: Programado com 5 níveis de investigação e 5 metros de espaçamento entre os eletrodos, com isso, alcança-se aproximadamente 60 metros de profundidade teórica de investigação. Para o desenvolvimento das linhas em campo estendeu-se os 4 cabos de 90 metros, atingindo os 360 metros de extensão total. O equipamento Syscal fica disposto no centro do arranjo de eletrodos.

- Arranjo Polo Dipolo: Programado com 7 níveis de investigação e 5 metros de espaçamento entre os eletrodos, com isso, atinge-se uma investigação teórica de até 80 metros de profundidade. No desenvolvimento do arranjo polo dipolo é preciso que um eletrodo remoto seja colocado a uma distância suficientemente longe da linha do levantamento (Loke, 2000).

É mantido assim o outro eletrodo fixo a uma distância denominada de "infinito" que corresponde a pelo menos dez vezes a maior abertura entre os eletrodos extremos do arranjo que permanecem na linha do levantamento (Keller \& Frischknecht, 1966; Telford et. al, 1990). Desta forma assegura-se que este tenha pouca influência sobre o resto do arranjo. Utilizou-se 500 metros de fio elétrico para satisfazer essa exigência e obter uma qualidade dos dados considerável. (Figura 3).

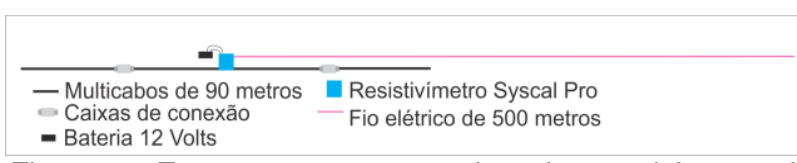

Figura 3 - Esquema representando o desenvolvimento do arranjo polo dipolo em campo.

Com o uso do software Prosys II (Fabricado pela Iris Instruments) fez-se a transferência de dados (equipamento - computador). O pré-processamento consistiu basicamente em i) inserção da topografia do perfil, ii) controle dos valores de resistividade inicial com a remoção de valores negativos, iii) seleção de uma faixa (range) de valores de resistividade inicial e iv) controle do desvio padrão dos valores. A partir deste procedimento foi gerado um arquivo e importado para o software Res2Dinv para o processo de inversão dos valores de resistividade elétrica aparente medida.

\section{Resultados e discussões}

Desenvolveu-se 8 arranjos do tipo Wenner Schlumberger e intercalado a estes, arranjos do tipo Polo Dipolo (devido a maior cobertura tanto em lateralidade quanto em profundidade). Os resultados gerados a partir dos arranjos Wenner Schlumberger apresentaram-se com baixa razão sinal/ruído e com aproximadamente 60 metros de profundidade de investigação. Para o procedimento de inversão dos dados foram consideradas 5 iterações e obteve-se erro calculado (RMS) com variação de 2,0 \% a 6,6\% nas seções finais.

Para os dados obtidos a partir do arranjo Polo Dipolo obteve-se, nas pseudoseções, aproximadamente 80 metros de investigação e maior cobertura lateral. $O$ erro RMS variou de $3,1 \%$ a $8,9 \%$. Os fatores que explicam o baixo erro são: i) Condições geomorfológicas do terreno, houve pouca influência da topografia na inversão dos dados, devido à baixa variação de altitude, ii) Umidade do solo, nos dias de aquisição de dados o 
solo estava úmido facilitando assim a penetração da corrente elétrica em subsuperfície, iii) Desenvolvimento do arranjo em campo com os cabos devidamente esticados e checagem constante da qualidade dos dados no módulo de leitura Syscal Pro.

A variação da escala de cores de 23.8 ohm.m até 16130 ohm.m foi selecionada devido ao melhor ajuste e correlação com o contexto geológico local no processamento e inversão dos valores de resistividade elétrica. Nas seções observou-se o contraste de resistividade elétrica marcando o contato entre rochas, saprólitos, solos, água superficial e subterrânea.

Nos resultados obtidos é importante levar em conta que as rochas podem ser tratadas como agregados heterogêneos de partículas sólidas, condutoras e/ou dielétricas compostos por espaços vazios preenchidos em proporções variáveis de eletrólitos aquosos. As propriedades elétricas dependem da textura e da composição mineral da matriz sólida, da geometria do espaço de poros e da proporção volumétrica de água nesses vazios (Mendelson \& Coehn, 1982; Sen et. al, 1988; Lima \& Sharma, 1990).

A variabilidade nos valores de resistividade elétrica registrados é devido a variações em impurezas, a imperfeições ou defeitos nos cristais dos minerais que constituem as rochas ou ainda, pela presença de microfissuras dos minerais, em geral cheio de fluidos (Parkomenko, 1967; Lima, 2014).

$\mathrm{Na}$ tabela 1 observa-se valores de resistividade elétrica de rochas e materiais presentes na área estudada conforme proposto por Telford et al. (1990).

\begin{tabular}{cc}
\hline Material & $\begin{array}{c}\text { Resistividade Elétrica } \\
\text { (Ohm.m) }\end{array}$ \\
\hline $\begin{array}{c}\text { Água em subsuperfície } \\
\text { (Rochas sedimentares) }\end{array}$ & $10-100$ \\
Quartzo (SiO2) & $4 \times 10^{10}-2 \times 10^{14}$ \\
Dolomito & $350-500$ \\
Argilas & $1-100$ \\
Margas & $20-100$ \\
Arenitos & $1-6.4 \times 10^{8}$ \\
Calcários & $50-10^{7}$ \\
Conglomerados & $2 \times 10^{3}-10^{4}$ \\
\hline
\end{tabular}

Tabela 1: Valores de resistividade elétrica dos materiais. Extraído de Telford et. al., 1990.

Nas seções L1, L2, L3, L4, L5 valores intermediários de resistividade elétrica relacionados a saprólitos, os baixos anômalos com rochas saturadas, argilosas ou margas foram observados. Os altos anômalos em subsuperfície estão associados a rochas maciças como zonas de calcário dolomítico fosfático. Essas áreas não apresentam nenhum tipo de cavidade, são zonas que apresentam altos valores de resistividade elétrica, podem estar relacionados também a zonas preenchidas por materiais maciços (Figura 4).

As seções L6, L7, L8 apresentam altos anômalos de resistividade elétrica correlacionados com rochas maciças e que indicam relação com dados anteriores, obtidos por sondagens a trado. Na porção leste observase a transição entre zonas de altos até baixos anômalos, marcando o contato entre a rocha sã, passando pelo saprólito e chegando até uma zona saturada com a presença de água em superfície, como observado no local de estudo (Figura 4).

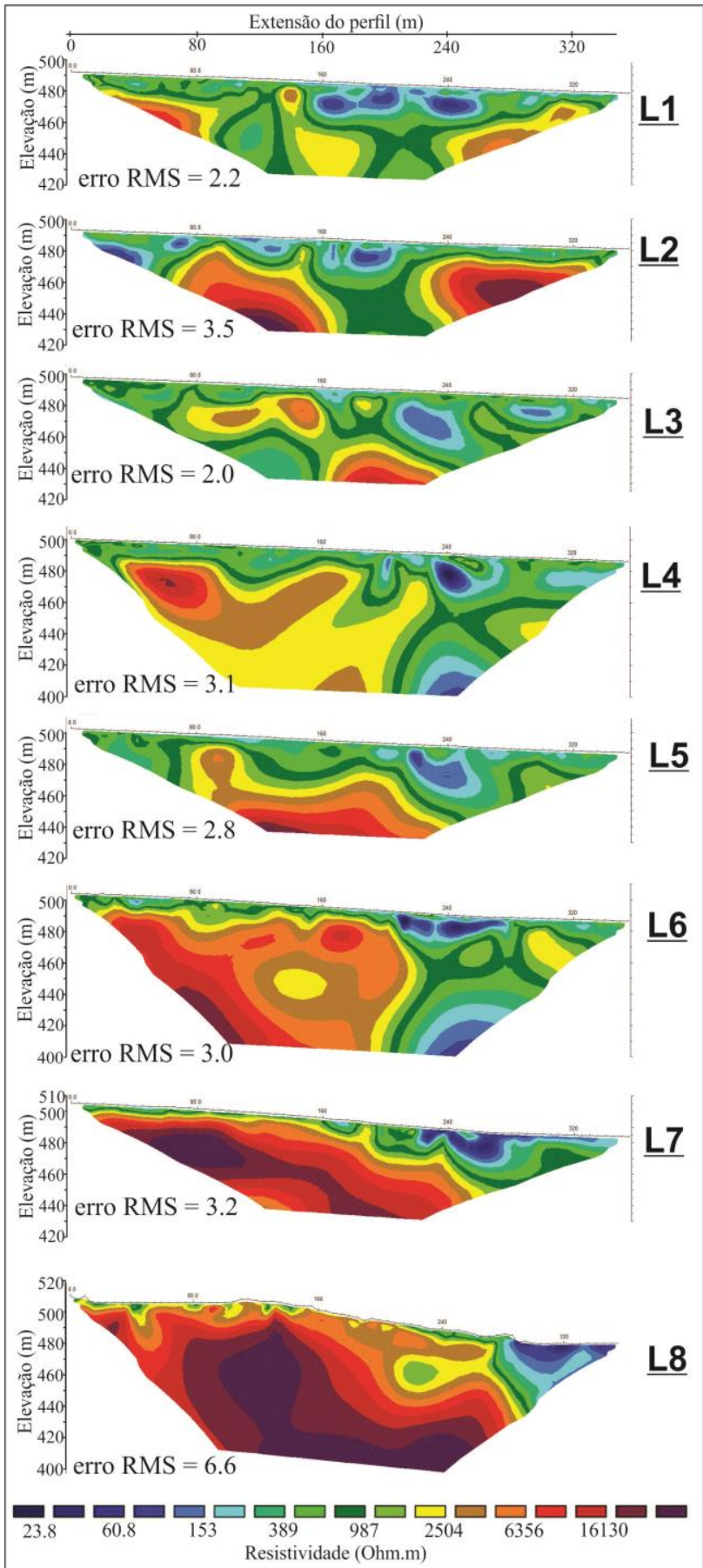

Figura 4 - Seções de eletrorresistividade de L1 a L8 da zona fosfática.

Devido a presença de um açude a leste da área os perfis L9 e L10 foram desenvolvidos deslocados para oeste. Os altos anômalos constantes têm relações diretas com as rochas sã presente no local como os fosforitos e calcários dolomíticos. As seções da porção sul da área 
estudada L11 e L12 apresentam o contato entre rochas maciças, saprólitos, rochas saturadas e água em subsuperfície (Figura 5).

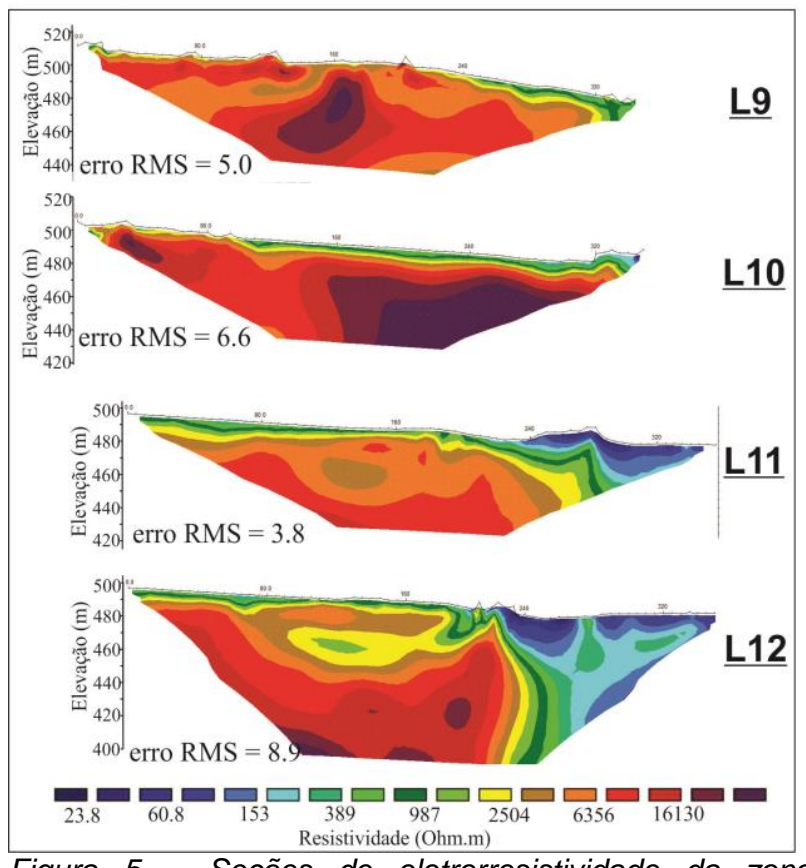

Figura 5 - Seções de eletrorresistividade da zona fosfática.

\section{Conclusões}

A aplicação do método geofísico de eletrorresistividade com o uso dos arranjos Polo Dipolo e Wenner Schlumberger mostrou-se eficaz e apresentou resultados satisfatórios e correlacionáveis com o contexto geológico da área de estudo. Permitiu identificar contatos entre rocha sã/saprolito e as zonas saturadas (freático). As técnicas de processamento e interpretação definiram a ausência de cavidades (zona cárstica) em todos os perfis investigados. Sugere-se, para uma melhor caracterização da área, o uso do método gravimétrico para a identificação das diferentes densidades dos materiais em subsuperfície.

\section{Agradecimentos}

Ao Laboratório de Geofísica Aplicada da Universidade Federal do Pampa, campus Caçapava do Sul por todo o suporte em todas as etapas executadas nesse projeto.

A EDEM, Empresa de Desenvolvimento em mineração e participações LTDA por ceder a área para pesquisas acadêmicas e seus colaboradores no auxílio da execução deste projeto, em especial ao Eduardo, Lucas, Glayson e Letícia.

Ao Orlando Leite, geofísico da Iris Instruments pelo auxílio na configuração das sequências de arranjos, préprocessamento e inversão de dados.

\section{Referências}

Boggiani, P. C. 1997. Análise Estratigráfica da Bacia Corumbá (Neoproterozóico) - Mato Grosso do Sul. São Paulo, IG-USP. Tese de Doutoramento (inédita).

CPRM. 1999. Programa de Levantamentos Geológicos Básicos do Brasil - PLGB. Folha SE.21-V-D - Porto Murtinho, escala 1:250 000. Brasília, CPRM, 88p.

CPRM. 2010. Banco de dados georreferenciados Geobank. Disponível em http://geosgb.cprm.gov.br/. Acesso em: 04 de abril de 2018.

Dentith, M \& Mudge, S. T. 2014 Geophysics for the mineral exploration geocientist. United Kingdom: Cambridge University Press. 438p.

EDEM - Empresa de Desenvolvimento em Mineração. 2017. Banco de dados em formato shapefile e informações geológicas da área de estudo.

Keller, G. V. \& Frischknecht, F. C. 1966. Electrical methods in geophysical prospecting. Oxford: Pergamon Press. 517p.

Lapido-Loureiro, F. E. \& Nascimento, M. 2003. Fertilizantes e Sustentabilidade na Agricultura: Uma Abordagem Mínero-QuímicaMetalúrgica, CETEM, [www.cetem.gov.br]/Publicações/Série Estudos e Documentos no 53.

Lima, O. A. L. de. 2014. Propriedades físicas das rochas: Bases da Geofísica Aplicada. Rio de Janeiro: Sociedade Brasileira de Geofísica. 342p.

Lima, O. A. L. de; Sharma, M. M. 1990. A grain conductivity approach to shaly sandstones. Geophysics, 55(10), p.1347-1356.

Loke, M. H. 2000. Eletrical imaging surveys for environmental and engineering studies: A pratical Guide to 2-D and 3-D surveys.

Mendelson, K. S \& Cohen, M. H. 1982. Effect of grain anisotropy on the electrical properties of sedimentary rocks. Geophysics, 47 (2), 257-263.

Parkomeno, E. I. 1967. Electrical Properties of Rocks. New York: Plenum Press Inc.

Sen, P. N; Goode, P. A e Sibbit, A. 1988. Eletrical conduction in clay bearing sandstones at low and high salinities. Jornal of applied Physics, 63(10), p.4832-4840.

Telford, W. M, Geldart, L. P, Sheriff, R. E. 1990. Applied Geophysics. 2ª Edição. New York: Editora Cambridge. 